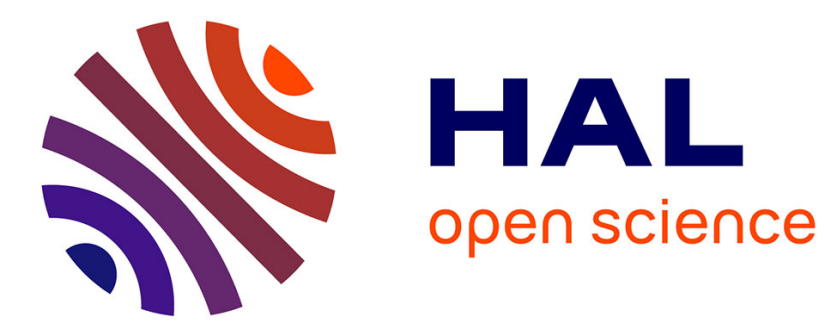

\title{
Remanent magnetization of fine particles
}

E.P. Wohlfarth

\section{To cite this version:}

E.P. Wohlfarth. Remanent magnetization of fine particles. J. Phys. Radium, 1959, 20 (2-3), pp.295297. 10.1051/jphysrad:01959002002-3029500 . jpa-00236037

\section{HAL Id: jpa-00236037 https://hal.science/jpa-00236037}

Submitted on 1 Jan 1959

HAL is a multi-disciplinary open access archive for the deposit and dissemination of scientific research documents, whether they are published or not. The documents may come from teaching and research institutions in France or abroad, or from public or private research centers.
L'archive ouverte pluridisciplinaire HAL, est destinée au dépôt et à la diffusion de documents scientifiques de niveau recherche, publiés ou non, émanant des établissements d'enseignement et de recherche français ou étrangers, des laboratoires publics ou privés. 


\title{
REMANENT MAGNETIZATION OF FINE PARTICLES
}

\author{
By E. P. WOHLFARTH, \\ Department of Mathematics, Imperial College, London, England.
}

\begin{abstract}
Résumé. - On passe en revue quelques calculs de l'aimantation rémanente des grains fins. D'abord, on a calculé la rémanence après saturation en-posant en prémisse diverses anisotropies. Puis on discute les courbes de rémanence acquises après application des champs directs ou alternatifs et on met en valeur quelques relations entre ces courbes.
\end{abstract}

Abstract. - A brief review is given of some calculations of the remanent magnetization of fine particles. The remanence after previous saturation has been calculated for a number of different types of anisotropy. A discussion is also given of remanence curves attained after application of D. C. or A. C. fields, and relations between such curves are pointed out.

1. Introduction. - The theory of the magnetic properties of single domain particles is now well known, and it is recognized that it can give at least a qualitative explanation of a wide range of experimental facts. More recently efforts have been made to extend and generalize the theory ; these extensions include, among others, discussions of particle interactions, variations of anisotropy, thermal fluctuations and multidomain and incoherent rotation effects. Although all these factors are doubtless important, the theory has as a result become so complicated that it is often difficult to make any physically significant deductions. It seems worth while, therefore, to return to the original theory and to calculate from it as much as possible. By comparing the results of such calculations with experiment, it should be possible to obtain some information, from the deviations which are usually observed, about the importance of the various complicating factors just mentioned.

Calculations of this type have been carried out for the remanent magnetization and related properties. Apart from the fact that such calculations are quite straightforward, the remanence of fine particles is important practically, for permanent magnet alloys, powder magnets, magnetic tapes, rock inclusions and thin films. As shown below, calculations of remanence are also possible for particles with mixed anisotropies, constituting a further extension of the theory.

2. Saturation remanence ; mixed anisotropies. For single domains with uniaxial anisotropy, the reduced remanent magnetization after previous saturation, $j_{\mathrm{R}}=I_{\mathrm{R}} / I_{0}$, is given by $j_{\mathrm{R}}=1 / 2$ for random and $j_{R}=1$ for aligned particles. For random particles with cubic symmetry Gans' calculations give $j_{\boldsymbol{R}}=0.831$ or 0.866 if the anisotropy constant $K$ has positive or negative values respectively. Wohlfarth and Tonge [1] have now generalized these results in two respects. Firstly, calculations of $j_{R}$ have been made for particles with $n$ equispaced equivalent easy directions of magnetization in a plane (such as occurs in haematite and some mixed hexagonal ferrites); it was found that $j_{\mathbf{R}}$ for a random assembly increases with $n$ as

$$
J_{\mathbf{R}}=\frac{1}{4} n \sin (\pi / n) .
$$

A similar discussion for $n$ easy directions arranged regularly in space also shows an increase with $n$. Secondly, the remanent magnetization for particles with mixed unequal anisotropies was calculated. The case of two uniaxial anisotropies, characterized by values of the constants $K_{1}$ and $K_{2}$ and of the angle $\beta$ between the two axes, was considered on the basis of two alternative expressions for the anisotropy energy, as dependent on the angle $\psi$ between $I_{0}$ and the $K_{1}$ axis, viz.

$$
\begin{aligned}
& E_{\mathbf{\Lambda}}^{(1)}=K_{1} \sin ^{2} \psi+K_{2} \sin ^{2}(\beta-\psi), \\
& E_{\mathbf{A}}^{(2)}=E_{\mathbf{A}}^{(1)}+\sqrt{\left(K_{1} K_{2}\right)} \sin ^{2} \beta \sin ^{2} \psi \sin ^{2}(\beta-\psi) .
\end{aligned}
$$

With $E_{\mathrm{A}}^{(1)}, j_{\mathrm{R}}=1 / 2$ for a random assembly; with $E_{\mathbf{A}}^{(2)}$, which includes a fourth order as well as a second order term, $j_{\mathrm{R}}$ is also close to $1 / 2$ unless $\beta$ is large and $K_{1} / K_{2}$ close to 1 , when $j_{\mathrm{R}}$ may increase towards a maximum value $1 / \sqrt{2}$; for a random variation of $\beta, j_{\mathbb{R}} \rightarrow 0.550$. Calculations on the basis of (2) have also been performed for coercive force but the results can not yet be reported.

Tonge and Wohlfarth [2] have also investigated the case of mixed uniaxial and cubic anisotropies, the former being characterized by an anisotropy constant $s$, the latter by $K(+$ or -$)$, as well as by the direction cosines with respect to the cube axes of $I_{0}(\alpha, \beta, \gamma)$ and the $s$-axis $(l, m, n)$. The anisotropy energy was taken to be

$E_{\mathbf{A}}=K\left(\alpha^{2} \beta^{2}+\beta^{2} \gamma^{2}+\gamma^{2} \alpha^{2}\right)-\mathrm{s}(\alpha l+\beta m+\gamma n)^{2}$. 
To calculate $j_{\mathrm{R}}$ the stationary values of $E_{\mathrm{A}}$ have to be obtained, and this was found to be virtually impossible generally. By considering the special cases $[l m n]=[100],[110],[111](K+$ or -$)$ and the general case roughly, it could, however, be established with some certainty that $j_{R}$ for a random assembly only differs significantly from $1 / 2$ if $s|| K \mid$ is less than $\mu_{c} \sim 1$.

3. Remanence curves. - The remanent magnetization considered above is that acquired after previous saturation. If a previously demagnetized assembly is subject to a field $H$ insufficiently large for saturation, it is possible to define a remanence curve $I_{\mathbf{R}}(H)$. This was calculated some years ago [3] for random uniaxial particles for which $j_{\mathbf{R}}(h)=0$ for $h \leqslant 1 / 2, i_{\mathbf{R}}(h)=1 / 2$ for $h \geqslant 1$, where $h$ is the usual reduced field. The $I_{\mathbf{R}}(H)$ curve is distorted by effects such as anisotropy variations. [3] Measurements of such curves (which are straightforward using Van Oosterhout's apparatus [4]) can give valuable information about the properties of particle assemblies.

Recently Wohlfarth [5] has derived simple relations between $I_{\mathbf{R}}(H), I_{\mathbf{D}}(H)$ and $I_{\mathbf{D}}^{\prime}(H)$ curves for uniaxial particles, the relations being valid whatever the degree of orientation and whatever the anisotropy variations. Here $I_{\mathbf{D}}(H)$ is the remanent magnetization attained after the previous acquisition of a remanence in a field $H_{0}$, say, followed by the application of a direct reverse field $H$. Also $I_{\mathbf{D}}^{\prime}(H)$ is acquired after application of a decreasing A. C. field [6], [7] with initial amplltude $H$. The relations are

$$
\begin{aligned}
& I_{\mathrm{D}}(H)=I_{\mathrm{R}}\left(H_{0}\right)-2 I_{\mathrm{R}}(H), \quad H<H_{0}, \\
& I_{\mathrm{D}}(H)=-I_{\mathrm{R}}(H) \quad, \quad H>H_{0}, \\
& I_{\mathrm{D}}^{\prime}(H)=I_{\mathrm{R}}\left(H_{0}\right)-I_{\mathrm{R}}(H), \quad H<H_{0}, \\
& I_{\mathrm{D}}^{\prime}(H)=0 \\
& H>H_{0} \text {. }
\end{aligned}
$$

Johnson [8] has made preliminary tests, which he is extending, of these relations, using $\gamma \mathrm{Fe}_{2} \mathrm{O}_{3}$ powders and with $H_{0} \rightarrow \infty$. The agreement with (4) is not unreasonable but with (5) it is rather poor, raising many interesting problems. Rimbert [7] has carried out A. C. demagnetization measurements on $\mathrm{Fe}_{3} \mathrm{O}_{4}$ powders, and again the agreement with (5) is not good. However, relation (5)* is approximately verified ; this result may presumably be derived more generally and is mentioned, for example, by Néel [9]. Kondorskij [10] derived relation (4) many years ago for an assembly of long parallel cylinders ; it is now seen that these relations have a wider applicability. From [4], also, the "remanence coercivity" $H_{\mathrm{R}}$ may be defined as

$$
I_{\mathbf{p}}\left(H_{\mathbf{R}}\right)=0, \quad \text { i.e. } \quad I_{\mathbf{R}}\left(H_{\mathbf{R}}\right)=\frac{1}{2} I_{\mathbf{R}}\left(H_{0}\right) ;
$$

measurements of $H_{\mathrm{R}}$, and particularly the ratio $H_{\mathrm{R}} / H_{\mathrm{c}}$, where $H_{\mathrm{c}}$ is the normal coercivity, may give valuable information about such matters as the variations of the anisotropy. For random non-interacting uniaxial particles with constant anisotropy, it is found that, for $H_{0} \rightarrow \infty$,

$$
H_{\mathrm{R}} / H_{\mathrm{c}}=1.094 \text {; }
$$

anisotropy variations tend to increase this ratio [11], [12].

4. Other results. - Other relevant results are concerned with the anhysteretic remanent magnetization which has been discussed in a simple manner [13], has often been measured and has some relevance in magnetic tape recording [14]. The effects of thermal fluctuations on the remanence and particularly the thermoremanence have been fully discussed by Néel [9] in relation to rock magnetism.

I am indebted to Dr. C. E. Johnson for advance information about his measurements.

\section{REFERENCES}

[1] Wohlfarth (E. P.) and Tonge (D. G.), Phil. Mag., 1957, 2, 1333.

[2] Tonge (D. G.) and Wohlfarth (E. P.), Phil. Mag., $1958,3,536$.

[3] Wohlfarth (E. P.), Research, 1955, 8, S 42.

[4] Van Oosterhout (G. W.), Appl. Sc. Research, B, 1956, 6, 101.

[5] Wohlfarth (E. P.), J. Appl. Phys., 1958, 29, 595.

[6] Johnson (C. E.) and Brown (W. F.), J. Appl. Phys., 1958, 29, 313, 1699.

[7] Rimbert (F.), C. R. Acad. Sc., Paris, 1956, 242, 890.

[8] Johnson (C. E.), private communication (see 6).

[9] NéEl (L.), Ann. Géophys., 1949, 5, 99.

[10] Kondors KIJ (E.), J. Phys., U. S. S. R., 1940, $2,161$.

[11] Bate (G.), Schofield (D.) and Sucksmith (W.), Phil. Mag., 1955, 46, 621.

[12] Haigh (G.), Phil. Mag., 1957, $2,877$.

[13] Wohlfarth (E. P.), Phil. Mag., 1957, 2, 719.

[14] Westmisze (W. K.), Philips Res. Rep., 1953, 8, 245.

\section{DISGUSSION}

Mr. Vonsouskij. - I want to draw attention to the work of Sur and Abel (Izo. Akad. Nauk. S. S. S. R., Ser. Fiz., 1952, 16, 703), in which they investigate the magnetic structure at remanence of a ring-shaped $\mathrm{Fe}-\mathrm{Si}$ monocrystal. The observation of Bitter-Akulov powder patterns has shown that the difference between the calculated $J_{\mathrm{r}}$ and the true $J_{\mathrm{r}}$ is due to the fact that the real domain structure has not been taken into account.

Mr. Wohlfarth. - My calculations were on magnetically hard small particles with no domain structure. I agree that multidomain effects, i.e. a domain structure of. perhaps, the type mentioned, 
may influence the remanent magnetization, but these are very difficult problems.

Mr. Hoselitz. - In some of your diagrams, you have shown experimental values of remanent magnetization higher than that expected without introducing domain interactions.

Do you think that these high values can be explained by taking this interaction into account?

Mr. Wohlfarth. - Yes, possibly.

M. Néel (remarque). - En introduisant une interaction convenable entre deux grains monodomaines, il est possible d'obtenir une aimantation rémanente négative.

$M r$. Sucksmith. - In view of the fact that for many ordinary materials $H_{\mathrm{r}} / H_{\mathrm{c}}$ is round about 1.3 irrespective of the type and magnitude of the anisotropy, is it a fair implication that the difference between the theoretical value of 1.094 is due to interaction?

Mr. Wohlfarth. - This may certainly be a part of the reason, but for small particle materials the variation of anisotropy (shape, etc.) would seem to be another factor. Again, further experiments directed towards these questions would be of great interest.

Mr. Lee. - I would merely like to suggest that further information about the remanent state might be obtained by simultaneous measurements of the remanent magnetization and remanent magnetostriction.

Mr. Wohlfarth. - Yes, this would be interesting since magnetostriction may be a more sensitive quantity than remanent magnetization. I hope you will carry out such measurements! 